\title{
Application of Web 2.0 Technologies in e-Government: A United Kingdom Case Study
}

\author{
Uthayasankar Sivarajah \\ Brunel Business School \\ Brunel University, UK. \\ cbpguus@brunel.ac.uk
}

\author{
Zahir Irani \\ Brunel Business School \\ Brunel University, UK. \\ zahir.irani@brunel.ac.uk
}

\author{
Stephen Jones \\ Conwy County Borough Council \\ Conwy, Wales. \\ steve.jones@,conwy.gov.uk
}

\begin{abstract}
Electronic government (e-Government) has endured significant transformation over the last decade and currently, it is making further leaps by incorporating modern technologies such as second generation web (Web 2.0) technologies. However, since the development and use of this kind of technology is still at its early stages in the public sector, research about the use of Web 2.0 in this domain is still highly tentative and lacks theoretical underpinning. This paper reports the preliminary findings of an in-depth case study in the United Kingdom (UK) public sector, which explore the application of Web 2.0 technologies in the local government authority (LGA). The findings elicited from the case study offer an insight into information systems (IS) evaluation criterions and impact factors of Web 2.0 from both a practical setting and an internal organisational perspective. This paper concludes that a combined analysis of the evaluation and impact factors rather than a singular approach would better assist the decision making process that leads to effective application of Web 2.0 technologies. It also highlights the significant impact and perceived effect of adoption of such technologies.
\end{abstract}

\section{Introduction}

Governments worldwide are striving to deliver more efficient and effective public services in order to meet the increasing demands and expectations of citizens whilst overcoming the major hurdle of reduced public budgets [1]. It is widely accepted in the existing literature that electronic government (e-Government) is much more complex than any previous efforts of ITinduced change experienced in the public sector $[2,3]$. For instance, the integration of new technologies in the e-Government domain poses a challenging task due to several factors such as the variability of its target audience in addition to the bureaucratic and political considerations.

The emergence of Web 2.0 has heralded new possibilities for many governments [4]. Web 2.0 technologies are simple and effective second generation web services that provide a social and participatory virtual platform for organisations to collaborate, network and interact with stakeholders [5]. Web 2.0 applications are now of significant relevance for many different domains of e-Government, besides the well-known examples of their use in facilitating political participation $[1,6]$. There are an increasing number of studies emerging on the implications of Web 2.0 on various public sector domains ranging from politics to health $[6,9]$. However, there is a dearth of research studies focusing on Web 2.0 and its application in the context of e-Government especially at a local government level. Also, the very few studies that exist in this domain lack theoretical underpinning and the backing of empirical research.

The main objective of this research is to create a contribution to fill the abovementioned void. Therefore, this study aims to present a comprehensive decision-making tool to aid local government authorities (LGAs) in their decision-making process surrounding Web 2.0 adoption. This will be achieved through the development of a theoretical model underpinned by IS evaluation criteria and impact factors from an internal organisational perspective to effectively aid Web 2.0 application in e-Government. This research project aims to contribute to the emerging field, specifically by focussing on the following research questions:

- How could LGAs approach an effective application of Web 2.0 technologies in the context of e-Government?

- What are the evaluation criteria that the LGAs can use to assess Web 2.0 technologies prior to its implementation?

- What are the implications of adopting Web 2.0 technologies by LGAs?

This paper is largely devoted to reporting the preliminary findings from an in-depth case study of a UK LGA. The remainder of the paper is structured as follows. Section 2 outlines the theoretical context of Web 2.0 application in e-Government. Section 3 briefly discusses the theoretical model and presents the research conjectures. Sections 4 and 5 present the research methodology and an outline of the case study background respectively. In section 6 , the authors report the preliminary research findings and synthesis. Finally, section 7 presents the conclusions, direction of future research and limitations respectively.

\section{The significance of Web 2.0 application in e-Government}

e-Government has been subject to significant transformation over the last decade. Currently, it is leaping even further by incorporating emerging technologies such as Web 2.0 that will not only 
enhance participation, transparency and integration but also speed up the pace of innovation [10]. The widespread use of Web 2.0 technologies by internet users has been seen by many as a potential turning point where a change in the role of the average web user was evident; one who was just as involved in service delivery as with service usage [1].

There have been many discussions in the eGovernment literature on the potential of Web 2.0 technologies for transforming governments. Mergel et al. [11] asserts that the explosion of these Web 2.0 technologies has given public institutions the potential to create real transformative opportunities in relation to their key issues of transparency, accountability, communication and collaboration and to promote civic engagement. According to Danis et al. [12], the use of social media sites by local governments can help them effectively manage resources and local knowledge, monitor and resolve issues in communities and engage with constituents in their own environment. The above authors clearly highlight the significant impact that Web 2.0 technologies have had on government organisations.

Many examples of government organisations embracing notable Web 2.0 technologies have already emerged from the UK and other countries. In the UK, social networking sites (i.e. Facebook), and Microblogging (i.e. Twitter), are said to be the most popular phenomena when compared with their European neighbours [13]. Yet, in all aforementioned cases, the use of Web 2.0 technologies is still a novel and challenging idea that it is not currently an integral part of the official governance policy of any government.

A review of the current literature [14, 15] mainly presents very few studies articulating systematic evaluation criteria that will aid government organisations in their decision-making process surrounding Web 2.0 adoption. Additionally, as the study of Web 2.0 is an emerging phenomenon in the government context and is still at its early stages, the existing studies lack theoretical underpinning and empirical grounding [16]. Against this backdrop, it is essential for the public sector, specifically local governments, to evaluate and understand the impact of Web 2.0 tools. This will help LGAs to identify the challenges and the added value when leveraging these technologies for the delivery of e-Government services. The authors are aware of the existence of future generations of web based technologies, often referred to as Web 3.0, Web 4.0 etc. However, their development is arguably still evolutionary and immature $[17,18]$. Therefore, they are not specifically discussed in this paper.

\section{Theoretical model for Web 2.0 application in e-Government}

The review of the existing literature has made it

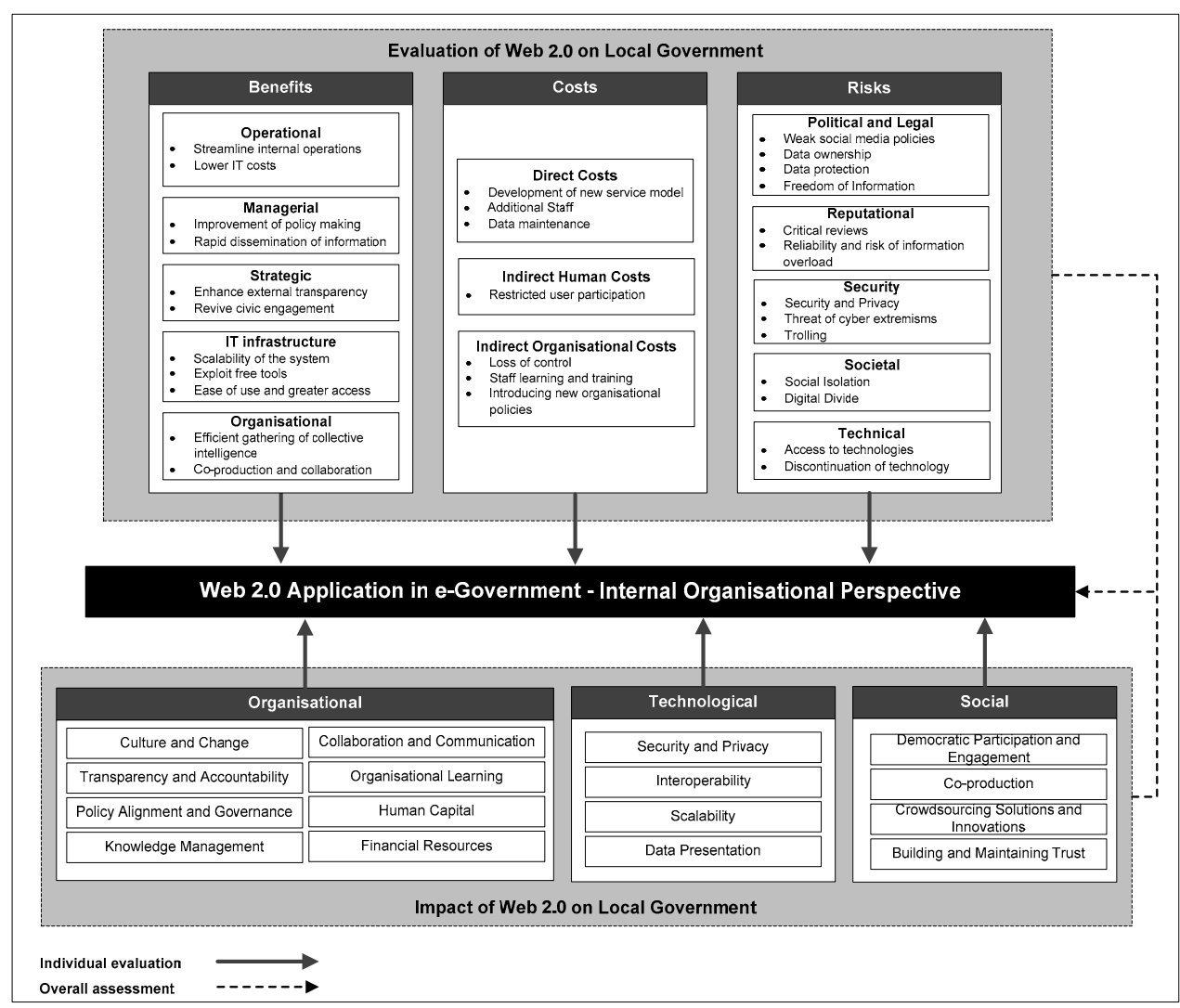

Figure 1. Proposed theoretical model for Web 2.0 application in e-Government 
evident that there is a need to further evaluate Web 2.0 technologies and understand its impact, especially in the context of e-Government. The literature in particular suggests that it is important for managers to evaluate information systems, especially understanding the benefits, costs and risks related with the financial and social capital investments of developing such infrastructures [19]. Failure to do so can lead to grave consequences such as inappropriate resource allocation [20]. However, if managers can better understand this, it can then help organisations to better utilise resources and improve their overall efficiency. Equally important is having an understanding of the potential impact that emerging technologies could inflict on these organisations. By its varied nature, Web 2.0 technologies allow unpredictable interactions between unexpected stakeholders producing unplanned results, none of which offer comfort to the typical government agency [21]. It is therefore vital for these authorities to understand the effects of such technologies in facilitating e-Government.

Theory development within research on the subject of use of Web 2.0 in e-Government is somewhat fragmented [16, 22]. As mentioned in the Introduction section, the existing literature on e-Government and IS has failed to address the issue of Web 2.0 application in this context. These have been the main motivators towards the development of a novel theoretical model that incorporates many significant factors from the existing literature on IS evaluation approaches and Web 2.0 impact factors. As an entirety, the theoretical model seeks to aid the effective application of Web 2.0 technologies in e-Government, more specifically for LGAs. It uses a holistic approach to cumulate all the disparate research studies that have been seen in isolation and bring them together in a single model. The theoretical model depicted in Figure 1 consists of:

- An evaluation of Web 2.0 using traditional IS evaluation practices that highlights the benefits, costs and risks of Web 2.0 for LGAs.

- A set of impact factors of Web 2.0 that has been systematically categorised into organisational, technological and social implications.

The rationale and descriptions of the chosen IS evaluation approaches and impact factors have not been discussed as these are beyond the scope of this paper. The model presents itself as a frame of reference that articulates a descriptive account of evaluation and impact factors that may need to be considered when leveraging Web 2.0 technologies in the context of e-Government. This model will be of particular relevance to government organisations such as LGAs as it seeks to provide them with a deeper understanding of factors that may encumber or encourage application of Web 2.0 technologies.

In order to test this model in the practical arena, this research presents seven conjectures to study the application of Web 2.0 in the context of eGovernment. A simplified version of the theoretical model including the conjectures is graphically illustrated in Figure 2.

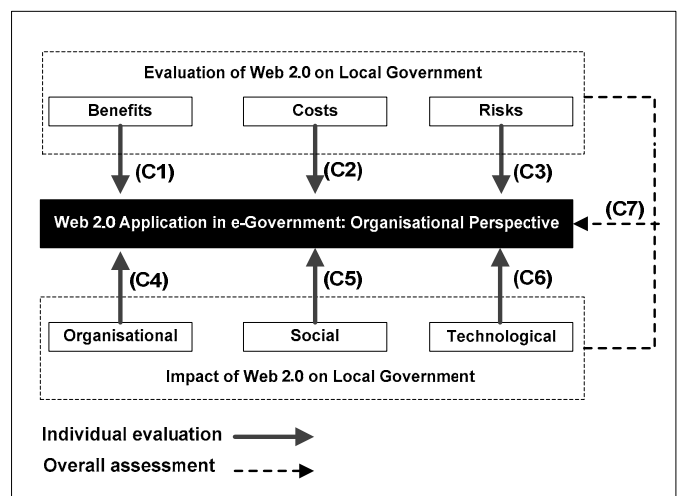

Figure 2. Proposed theoretical model including research conjectures

- (C1, C2, C3): Evaluating the benefits $(\mathrm{C} 1)$, costs (C2), and risks (C3) of Web 2.0 will aid the effective application of Web 2.0 in the eGovernment context.

- (C4, C5, C6): Exploring the organisational (C4), technological (C5), and social (C6) impact of Web 2.0 will aid the effective application of Web 2.0 in the e-Government context.

- (C7): Evaluating Web 2.0 and exploring the impact of Web 2.0 together will provide a cohesive tool to aid the effective application of Web 2.0 in e-Government.

The formulation of this model is therefore significant as it can facilitate LGAs and researchers in making robust decisions surrounding Web 2.0 application in e-Government.

\section{Research methodology}

In view of the nature of this research, the choice of methodology was influenced specifically by the rapid evolution and prominence of the use of Web 2.0 technologies by government organisations and the need to capture rich contextual information to answer the underlying research questions. Additionally, research into the adoption of new technologies highlights the need to consider a plethora of factors that broadly fall into human, organisational and technological categories. Therefore, this prompted the need to consider the involvement and participation of government organisations and their staff so that their experiences and knowledge on the adoption of Web 2.0 technologies can be exploited. Thus, allowing for the development of effective IS evaluation and impact criteria for Web 2.0 application in the e-Government domain.

A case study strategy that uses qualitative research methods for theory testing was chosen for this research in account of its originality and exploratory nature; see for example, Hakim [23] and Yin [24]. There are a 
multitude of reasons behind the use of such a strategy, for example it could be considered suitable to describe a phenomenon, build theory or test theoretical concepts or relationships, or a combination of all three[24]. In this instance, it was used with the objective of achieving all of the three purposes listed above.

The case organisation used for this research was suitably selected only if the employees of a LGA had been extensively using various Web 2.0 technologies for work purposes for a considerable amount of time. However, as the case chosen was not systematically sampled, the findings cannot be generalised to a wider population of LGAs. Despite this limitation, this paper provides a significant contribution towards analysing the IS evaluation criteria and the impact of the use of Web 2.0 technologies by LGAs.

\subsection{Data collection}

Empirical data was primarily gathered by conducting in-depth semi-structured interviews with local government authorities and participant observation $[25,26]$. In doing so, their insights into the use of Web 2.0 technologies and its impact on the authorities in the context of e-Government were also gathered. The reliability of the research methods were established through a pilot case study. This pilot study was initially conducted with a senior manager from another UK LGA that helped improve the quality of the research, as issues such as ambiguity and vagueness represented in the interview agenda, could be addressed.

The improved interview agenda was then used with the suitably chosen LGA to facilitate the collection of rich relevant case study data, by allowing the researcher to steer the interview process, and ask standardised questions. However, it also allowed the interviewee to have sufficient freedom to discuss related issues. Additional data gathering research methods and lines of enquiry included obtaining porting evidence through informal conversations; policy documents; IT corporate strategy report; minutes from meetings and consultancy reports. The use of multiple methods ensured data triangulation, thus contributing towards the reliability and validity of the findings for this study. These findings have also been crosschecked with the LGA chosen for the case study as part of the triangulation process to further validate the results.

The interview protocol underwent the standard university process to obtain ethical approval for data collection methods and mode of collection. The authors took much care to ensure the data collection process was not contaminated by data bias. As part of the research design, an approach similar to that used by Molla et al. [27] was used for data collection, analysis and checking while conducting the initial exploratory research.

\subsection{Interview process}

Interviews were conducted with those who were considered to be independent and most knowledgeable when it came to the human, organisational and technical factors associated with the adoption and use of Web 2.0 technologies within the case environment. Only the senior and experienced users of Web 2.0 technologies were interviewed. The job functions of the interview participants (to elicit data) were Head of ICT (SJ); Corporate e-Government Manager (SD); Website Manager (RSJ); IT Systems Manager (RJB); IT Services Manager (PU) and IT Support Manager (NP). The duration of each of these interviews was approximately one hour and fifteen minutes, where every interview was conducted on a 'one-to-one' basis so as to stimulate conversation and break down any barriers that may have existed between the interviewer and interviewee. Apart from this, three informal interviews were also conducted as part of secondary lines of enquiry. These participants were also users of Web 2.0 technologies and their job functions were, Finance Manager; Social Services Information Manager and Service Improvement Manager. The duration of each of these interviews were approximately thirty minutes and was also conducted on a 'one-to-one' basis. All of the abovementioned interviews took place in a bookable meeting room, which was away from the normal office environment with no disruption. The verbal and non-verbal responses of the respondents during the interview were also taken into account as part of the feedback.

\subsection{Case study validity}

There was a need to address internal validity to ensure the robustness of the findings due to the use of interviews, documentary sources, and observation in this study. Therefore, each interview was digitally recorded and subsequently transcribed. These were then sent back to the interview participants to check and resolve any discrepancies that may have arisen and to eliminate interviewer bias. Additionally, great care was undertaken by the authors to ensure that the collected data converged around similar facts rather than emotion due to the array of evidence collected in this research. The procedures used in conducting the study and the use of triangulation for data collection (see, for example, Jick, [28]) contributed to the reliability and validity of the study, while complying with the recommendations of Pan and Tan, [29]. Therefore, the researchers have full confidence in the accuracy of the research process and the findings.

\subsection{Data analysis}

The data derived from the case study was triangulated and then analysed to draw empirical conclusions. This study adopted a qualitative data 
analysis technique and used NVivo software (Qualitative analytical tool) to support the development of the coding system used for data analysis. The process of data analysis involved examining the meaning of peoples' words and actions (e.g. Ramanath, [30]). These findings were used to develop the empirical evidence reports that support the theoretical model for application of Web 2.0 technologies in e-Government.

\section{Background to the case}

The case study is a public sector organisation which has been established for 18 years (since 1995) to provide a range of public services, including Education, Social Services and Highways. The population is 160,000 , staffing establishment is 7,500 and the annual revenue budget is $£ 350 \mathrm{~m}$.

The Information, Communications and Technology (ICT) Department is headed by the Head of ICT and forms part of a corporate support services directorate. The ICT department's two main functions are to facilitate corporate IT strategy and policy, and to provide comprehensive ICT services to support corporate and user departmental objectives. There are 80 staff within the ICT department and the IT infrastructure comprises of approximately 5500 computers and laptops, 180 sites, 200 servers and 220 departmental and corporate IT systems. The LGA's website has been recently accredited by SOCITM, an IT professional body for UK LGAs as a '3star' website, identifying it as one of the best in the UK and an example of good practice. The LGA used as the case extensively uses modern technologies such as cloud computing and Web 2.0 for both internal operations by employees and external engagement with citizens. Thereby, it fulfils the selection criteria of this case study.

\section{Research findings and synthesis}

In the following subsections, an analysis and synthesis of four key areas have been elicited from the empirical work - Web 2.0 Strategy and its Application in the Case Organisation, IS evaluation: A Web 2.0 perspective, Impact of Web 2.0 and Overall Assessment of Web 2.0 application in the Case Organisation - are presented. It is important to emphasise that findings drawn from the case study while cannot be generalised, may still be generally useful [31]. The first area of discussion is Web 2.0 strategy, and its application in the case organisation is reported below.

\subsection{Web 2.0 strategy and its application in the case organisation}

The adoption of any new technology in a public sector organisation often aims to meet the goals of the government's ICT strategy and involves the development of a business case [32]. In this case, when the Head of ICT and the senior managers were asked if there was a formal strategy in place for adopting Web 2.0 strategies in their LGA, all the interviewees responded that there was no such strategy in place. According to the Head of ICT, the department felt that an overall ICT strategy of the LGA was sufficient and adoption of Web 2.0 did not need a strategy of its own as it would get outdated very quickly.

With regards to the decision making process for the use of Web 2.0 within the case organisation, this was ultimately made by the Head of ICT and the senior management team within the IT department. However, the decision to implement Web 2.0 technologies was described as obvious because the organisation wanted to keep up with the technological changes and maintain their reputation. The IT department felt that they wanted to be seen as keeping up with the technological changes and did not want to be left behind by ignoring it. This resonates with the view of Charlton [13] who highlighted that some public sector organisations are jumping on the bandwagon to only keep up with technological changes and maintain reputation. Thus, asserting that decision-making in the public sector is not always based upon accounting and economics. Other motivational factors for implementing Web 2.0 highlighted by the rest of the management team were to plug gaps in communications and engagement, make these technologies available to users and provide greater accessibility, and finally to achieve business efficiency.

Though the case organisation highly embraced the use of Web 2.0 technologies for internal work purposes, there still remained some resistance and lack of commitment from some internal users to exploit Web 2.0 tools to improve their respective service areas. According to the Head of ICT, all the employees did not use platforms such as Facebook or Twitter. Instead, these applications were used where a business use was seen. Ultimately, the use of Web 2.0 tools is under the jurisdiction of the Head of ICT and the IT management.

\subsection{IS evaluation: A Web 2.0 perspective}

It is certain that IS evaluation is definitely an important process prior to implementing a new system [33]. Hence, the findings of this evaluation analysis at the pre-implementation stage will be invaluable to government organisations. This concurs with the views of all the interviewees who suggested that it is extremely important to perform a formal IS evaluation prior to implementing a new technology. However, it was interesting to note that while they signify IS evaluation as an important procedure to follow, there was no formal evaluation that was conducted on Web 2.0 technologies prior to its adoption. The Head of ICT stated that as the majority of Web 2.0 applications 
were free of cost, only an informal discussion about the benefits, drawbacks and risks was conducted prior to its implementation.

The chosen IS evaluation approaches consisted of benefits, costs and risks factors proposed by Shang and Seddon [34], Irani and Love [33], Evangelidis et al. [35] and Schwartz [36] respectively. The IS evaluation approaches form the IS evaluation segment of the conceptual model (as illustrated in Figure 1), which helps LGAs understand the real benefits, costs and risks of using Web 2.0 applications in the context of e-Government prior to its implementation. This resonates with the responses from all the participants highlighting that evaluation of benefits, costs and risks of Web 2.0 technologies together would better influence their decision in adopting these technologies. This supports the study's research conjectures $\mathrm{C} 1, \mathrm{C} 2$ and $\mathrm{C} 3$. The Head of ICT and e-Government manager raised concerns that this was an area in need of greater focus in the future, given the lack of a formal evaluation process for these technologies. They also reported that the costs of implementing Web 2.0 tools had been ignored as generally the biggest cost of a new system would be the technology itself, which in this case was free. However, according to the eGovernment manager, the LGA now needed to be more careful in view of the rising indirect costs as the organisation was now diverting more staff resource and spending more time with these technologies, all of which result in additional costs.

The findings from the benefits, costs and risks evaluation of Web 2.0 technologies in the case organisation are reported below.

\subsubsection{Benefits evaluation of Web 2.0 technologies}

There is potential for Web 2.0 tools to create a public sector paradox especially in government organisations. Therefore, a systematic benefit evaluation is necessary prior to placing government information and providing services online using Web 2.0 tools, as the integration of these technologies in eGovernment should not be done arbitrarily $[14,15]$.

The benefits evaluation criteria consist of the following dimensions; operational, managerial, strategic, IT infrastructure and organisational. These dimensions were used to evaluate the benefits of Web 2.0 as the classifications covered a broad spectrum of functions surrounding an organisation. Managerial benefits of Web 2.0 such as rapid dissemination of information, strategic benefits such as enhancing external transparency and reviving civic engagement and finally IT infrastructure benefits such as exploiting free tools and ease of use and greater access had been considered by the interviewees to be highly important factors for the effective application of Web 2.0 tools in the case organisation. For instance, the Website manager stated that rapid dissemination of information was an extremely important managerial benefit. This was because Web 2.0 tools such as Twitter were very efficient in supporting LGA's management team to disseminate information to a vast number of users at a great speed, compared to other methods of communication such as static websites or printed newsletters. This finding resonates with Buchanan and Luck [37]. On the contrary, the managerial benefit of using Web 2.0 tools to improve policymaking [16] was not believed to be of great importance by most managers interviewed. The e-Government manager stated that it was not at all important, and the Website manager highlighted that although in principle it made perfect sense to use these tools, in reality policies are implemented by a self-selected group of policymakers.

In addition to the benefits of Web 2.0 derived from the literature, the Head of ICT and the IT Systems manager both added that Communication and Marketing of Services were two other important strategic benefits of Web 2.0 that was of significance for the decision making process of its application. Though marketing is quite certainly the primary use of these tools in the private sector, it is interesting to note that marketing of LGA's existing services with internal employees also seemed quite a prominent and an effective use of these tools in the case organisation.

\subsubsection{Costs evaluation of Web 2.0 technologies}

While it is important to assess and recognise the benefits of an information system in order to complete a robust IS evaluation, it is equally important to understand the cost implications of an IS project [33] . According to Hochstrasser [38], the real costs of an IT/IS deployment can often be divided into direct and indirect cost factors. Therefore, the cost evaluation criteria developed in this research presents both direct and indirect human and organisational costs adopted from Irani and Love [33].

One of the key direct costs of Web 2.0 technologies that the interviewees highlighted was data maintenance. The e-Government manager asserted that this was a significant factor as the case organisation is generally good at putting information out but not as good when it comes to tidying up the data once it becomes outdated. With regards to indirect organisational costs, introducing new organisational policies was considered to be highly significant. This resonates with the findings of Bertot et al. [39], where the authors stated that as many social media services are hosted outside government websites (e.g., Facebook, Twitter, YouTube), it is important for government agencies to establish and enforce explicit agency-wide linking policies. This can be both time consuming and costly for such organisations.

Apart from the existing costs derived from the literature, the Website manager also highlighted that use of personal time for monitoring and brokering Web 2.0 applications was a highly significant indirect human cost for the LGA. The manager stated that the fact that the users had to personally monitor council's social media sites and respond to Twitter 
communication meant that it was a highly time consuming task resulting in the loss of focus on their day-to-day duties.

\subsubsection{Risks evaluation of Web 2.0 technologies}

As IS projects are renowned for their high failure rate, it is important for organisations to improve their ability to manage these risks so that projects can be delivered against the objectives with which they were justified [19]. The risk dimensions outlined in this research are political and legal, reputational, security, societal and technical.

Unsurprisingly, the interviewees considered security and privacy as the most significant technological risk factor of Web 2.0 tools that needed consideration before adoption. This finding concurs with the view of Bin Al-Tameem et al., [40] who noted that the open nature of Web 2.0 presents significant challenges to the traditional enterprise approach to controlling intellectual property over information shared and surety of these applications. Risk of information overload and reliability was also highlighted as a significant reputational risk that had to be taken into account before implementing these tools. This finding resonates with the view of Huijboom et al., [41], where the authors highlighted that there is a risk of information overload and poor quality of content shared by users of certain Web 2.0 applications such as blogs and wikis, as concerns are raised about the reliability, accuracy and authority of their information.

On the contrary, discontinuation of technology was not believed to be a significant technical risk by the management although Bertot et al. [39] asserted this as a risk in the literature. The authors raised concerns over the risk of the continuity of existing Web 2.0 tools. For instance, Yahoo's announcement of the discontinuation of its 'delicious' tagging service presents such an example. However, according to the e-Government manger, Web 2.0 tools are a supplement to the other methods they use traditionally, so it will not be an issue to the LGA if they were to be discontinued. Apart from the Web 2.0 risks derived from the existing literature, the IT support manager highlighted that integration and interface to other systems was a technical risk of Web 2.0 tools that needed to be considered prior to its adoption. The manager believes that integrating some Web 2.0 tools to the existing systems in the organisation could prove both challenging and time consuming.

\subsection{Impact of Web 2.0 on the LGA}

Since the deployment of such technology is at its early stages in the public sector, research about the impact of Web 2.0 technologies are still highly tentative and exploratory [41]. Hence, the postimplementation findings of this impact analysis will be invaluable to government organisations as they aim to determine the level of use of these technologies by LGAs and assess if they are relevant and necessary in order to propose areas for improvement and future action plans. This resonates with the responses from the ICT management team where they felt that understanding the impact of the decision to adopt Web 2.0 technologies prior to implementation would definitely have helped influence their decisions.

The key focus within this study is the use of Web 2.0 for local governments and to facilitate their internal operations and services. Therefore, the chosen three classifications to articulate the implications of such technology were organisational, technological and social implications. These have been classed as important antecedents of IS success and have been envisaged to contribute greatly to the IS success of an organization by scholars $[42,43]$. This concurs with the views of the senior managers and the head of ICT who all mentioned that it would definitely be helpful and provide a holistic view, which in turn will benefit the LGA. This supports the study's research conjectures C4, C5 and C6. The e-Government manager stated that the social and organisational impact was one of the key drivers for implementing Web 2.0 technologies and an assessment on whether this could be achieved would affect the decisionmaking process.

Table 1 provides an analysis of the impact factors of Web 2.0 based on the views of the interviewees

Table 1. Impact of Web 2.0 technologies on the case study organisation

\begin{tabular}{|c|c|c|c|c|c|c|c|}
\hline 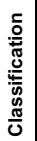 & Impact Factors & 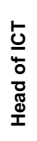 & 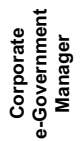 & 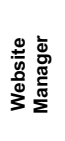 & 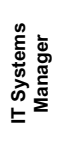 & 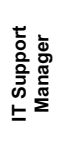 & 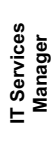 \\
\hline \multirow{8}{*}{ 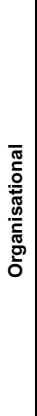 } & Culture and Change & 0 & O & O & O & 0 & 0 \\
\hline & $\begin{array}{l}\text { Transparency and } \\
\text { accountability }\end{array}$ & $\odot$ & $\odot$ & O & O & 0 & O \\
\hline & $\begin{array}{l}\text { Policy Alignment and } \\
\text { Governance }\end{array}$ & O & 0 & 0 & O & O & O \\
\hline & $\begin{array}{l}\text { Knowledge } \\
\text { Management }\end{array}$ & $\odot$ & 0 & 0 & $\odot$ & O & O \\
\hline & $\begin{array}{l}\text { Collaboration and } \\
\text { Communication }\end{array}$ & $\odot$ & $\odot$ & O & 0 & $\odot$ & $\odot$ \\
\hline & Organisational learning & O & O & O & O & $\bullet$ & O \\
\hline & Human Capital & $\odot$ & $\mathrm{x}$ & 0 & $\odot$ & 0 & $\mathrm{x}$ \\
\hline & Financial Resources & 0 & $\mathrm{x}$ & 0 & 0 & $\odot$ & 0 \\
\hline \multirow{4}{*}{ 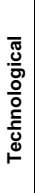 } & Security and Privacy & $\bullet$ & O & O & O & $\odot$ & $\odot$ \\
\hline & Interoperability & 0 & $\odot$ & 0 & 0 & 0 & $\odot$ \\
\hline & Scalability & 0 & 0 & 0 & $\mathrm{x}$ & $\odot$ & O \\
\hline & Data Presentation & ○ & $\odot$ & O & O & $\odot$ & O \\
\hline \multirow{4}{*}{$\begin{array}{l}\bar{\pi} \\
\bar{c} \\
\infty\end{array}$} & $\begin{array}{l}\text { Democratic Participation } \\
\text { and Engagement }\end{array}$ & 0 & $\odot$ & 0 & 0 & $\odot$ & O \\
\hline & Co-production & O & $\odot$ & O & $\odot$ & O & $\odot$ \\
\hline & $\begin{array}{l}\text { Crowdsourcing solutions } \\
\text { and Innovations }\end{array}$ & $x$ & $x$ & O & O & O & O \\
\hline & $\begin{array}{l}\text { Building and Maintaining } \\
\text { Trust }\end{array}$ & $\bullet$ & $\odot$ & $\odot$ & O & $\odot$ & $\bullet$ \\
\hline
\end{tabular}


using a 7 point Likert scale of 'less significant to fairly significant' $(O)$, 'moderately significant to significant' (๑) and 'highly significant to extremely significant' $(\bullet)$. For questions where the interviewees stated "not significant', an " $x$ " symbol has been used.

The findings from the organisational, technological and social impact analysis of Web 2.0 technologies in the case organisation are discussed below.

\subsubsection{Organisational impact of Web 2.0 technologies on LGA}

Web 2.0 provides a new set of technologies to government organisations. However, at the same time, it brings about a change in the existing organisational culture of participation, openness and transparency. The impact on collaboration and communication was highlighted as the most significant organisational implication of Web 2.0 technologies on the case organisation. This finding concurs with the view of Schweik [44], who highlighted that the internal and external collaboration and communication within an organisation is better facilitated by Web 2.0 tools. The interviewees stated that communication and collaboration within departments have been more efficient using collaborative tools such as Google's 'Apps for Business' and Yammer.

The implication of Web 2.0 technologies on culture and change was considered to be of less significance on LGA by the majority of the interview participants. In the literature, Parycek and Sachs [45] highlighted that the adoption and implementation of Web 2.0 tools requires government organisations to embrace innovation, transparency, collaboration, open communication and user-generated content. The Head of ICT and the IT support manager both believed that Web 2.0 technologies had not had a substantial effect on the LGA within this context, as the staff have been open to the change in terms of embracing new technological changes. The senior managers believed that this was because the LGA operates an 'open culture' policy. This view was also echoed across senior managers from non-IT departments such as the Highways and Finance departments when interviewed on an informal basis to crosscheck results and avoid bias.

\subsubsection{Technological impact of Web 2.0 on LGA}

As ICT rapidly develops, it is important for organisations to understand the technical implications of these developments [46]. The technological dimension in the proposed theoretical model reflects the influences of Web 2.0 tools on the technical front of a local government organisation.

Not surprisingly, security and privacy was reported as a significant technological implication by the LGA management team. This resonated with the findings of authors such as Osimo, [1] and Chen et al. [47], where they reported that government organisations need to be aware of security and privacy concerns as Web 2.0 technologies leave organisations more vulnerable to issues such as loss of information, hacking and cyber extremism. However, the authors also highlighted that a balance between tight security without stifling creativity and communication needed to be achieved.

The interviewees considered that the potential of Web 2.0 tools to allow data presentation in various methods was not a significant implication for the LGA. According to Meijer [48], information can be shared and presented in a variety of new ways beyond traditional methods with the aid of Web 2.0 tools, thus enabling better data presentation. Although the case findings did not resonate thoroughly with Meijer's views, the management felt that they had not extensively exploited such practices to have a significant implication in data presentation.

\subsubsection{Social impact of Web 2.0 technologies on LGA}

A key feature of Web 2.0 is that it allows for usergenerated content and this is often perceived to have major social implications. One of the main social impacts that Web 2.0 technologies has had in the case organisation is on building and maintaining trust. A study by Grabner-Krauter [49] on the role of trust in Web 2.0 suggests that continuous interactions and positive experience in social networking sites will enhance the initial trust of the user. This resonates with the case study finding where the interviewees echoed that regular interaction with users via social media technologies helped build and maintain trust. Similarly, most of the IT management team also reported co-production as a significant social implication of Web 2.0 tools to the LGA. This concurs with the view of Bertot et al. [39], where the authors asserted that government employees could use Web 2.0 tools to work with the public to get their involvement in design, development and delivery of services, thus building a two-way relationship.

On the contrary, the impact of Web 2.0 technologies on triggering innovations and crowdsourcing solutions in the LGA was not considered as being significant across the management. According to Bertot et al., [39] the use of Web 2.0 tools spark innovation through sharing of knowledge and helps support crowdsourcing (i.e. distributed problem solving and production model outsourced to a group of people). However, this was not the case in the LGA.

\subsection{Overall assessment of Web 2.0 application in the case organisation}

As the above research findings and synthesis highlights, Web 2.0 can have a significant impact on transforming government organisations. The Head of ICT and the IT management team stated that both 
evaluation of Web 2.0 technologies and exploring its impact on the LGA together would better influence their decision prior to adopting these tools. According to the IT management team, with new and rapid technological changes, singular use of the traditional IS evaluation approaches such as analysing benefits, costs and risks is no longer sufficient. Therefore, merging these along with impact factors of Web 2.0 application provides them with a holistic tool. Thereby, it supports the study's final research conjecture $\mathrm{C} 7$.

When management were asked about their perception of whether the adopted Web 2.0 technologies were a success whilst stating their criteria for success, most of them responded positively, stating that they thought these technologies were well exploited. The e-Government manager also highlighted that the adoption of Web 2.0 technologies was a success. The manager stated that one criterion to measure success was quality in terms of up-to-date information currently being published on social media websites such as the LGA's Facebook page. This was in stark contrast to 18 months ago when much of the information was outdated. The manager also spoke about the challenges of restricting rogue operations such as reviews or comments which could damage reputation but had to be controlled in a professional manner.

\section{Conclusions}

The literature and the empirical findings of the case study highlighted that the uptake of Web 2.0 technologies in the public sector is no longer a new phenomenon, thus making government organisations more amenable to exploiting such technologies. The main aim of the paper has been achieved by articulating the preliminary findings from an in-depth case study conducted in a UK LGA. This research contributes at both a theoretical and empirical level towards the enhanced understanding of the significance and the implications of using Web 2.0 technologies in government organisations. This study provides preliminary answers to the three research questions posed in the introduction. These answers are presented below as three key conclusions elicited from this research in respective order.

- A combined analysis rather than a singular approach in using IS evaluation criteria (i.e. benefits, costs and risks) and impact factors (i.e. organisational, technological and social) would better assist the decision-making process and lead to an effective application of Web 2.0 technologies in e-Government.

- The results reported mixed outcomes over the IS evaluation criterions considered for Web 2.0 tools in the case organisation. However, the adoption of Web 2.0 tools have been well received by the employees and effectively supported by the ICT department. The unrestricted support given by the
ICT department and LGA for the use of such technologies by employees was vital to the effective application of the Web 2.0 technologies.

- The introduction of Web 2.0 technologies does not appear to have had as big an impact on the case organisation as anticipated by the ICT Department. This is evidenced in the findings from Table 1. This could be a result of Web 2.0 tools not being exploited to their maximum potential within the organisation and therefore requires further analysis.

These conclusions are in keeping with the research conjectures. This study now requires further analysis of the empirical data which can be used to test the conjectures thoroughly, thus allowing for refinement of the proposed model and providing definite answers to the research questions. The main limitation of this study is the confinement of the research context to LGAs in the UK. Despite its limitation, this study will provide significant empirical evidence regarding the evaluation and impact of the application of Web 2.0 technologies by LGAs.

\section{References}

[1] D. Osimo, "Web 2.0 in Government: Why and How?", 2008, European Communities, Luxembourg

[2] Z. Irani, Y.K. Dwivedi and M.D. Williams, "Understanding consumer adoption of broadband: an extension of the technology acceptance model", J.Oper.Res.Soc., 60(10), 2009, pp. 1322-1334.

[3] V. Weerakkody, Y.K. Dwivedi, L. Brooks, M.D. Williams and A. Mwange, "E-government implementation in Zambia: contributing factors", International Journal of Electronic Government, 4(4), 2007, pp. 484-503.

[4] D. Osimo, D. Campbell, J. Kerr-Stevens, C. Bishop and L. Bryant, "Public services 2.0: Web 2.0 from the periphery to the centre of public service delivery", 2009,.

[5] T. O'Reilly, "What is Web 2.0: Design Patterns and Business Models for the Next Generation of Software", International Journal of Digital Economics, 65, 2007, pp. 17-37.

[6] S. Wattal, D. Schuff, M. Mandviwalla and C. Williams, "Web 2.0 and politics: the 2008 U.S. presidential election and an e-politics research agenda", MIS Quarterly, 34(4), 2010, pp. 669-688.

[7] S. Anfinnsen, G. Ghinea and S. de Cesare, "Web 2.0 and folksonomies in a library context", International Journal of Information Management, 31(1), 2011, pp. 63-70.

[8] B. Hughes, I. Joshi, H. Lemonde and J. Wareham, "Junior physician's use of Web 2.0 for information seeking and medical education: A qualitative study", International Journal of Medical Informatics, 78(10), 2009, pp. 645-655.

[9] H. Ajjan and R. Hartshorne, "Investigating faculty decisions to adopt Web 2.0 technologies: Theory and empirical tests", The Internet and Higher Education, 11(2), 2008, pp. 71-80.

[10] P. Drogkaris, S. Gritzalis and C. Lambrinoudakis, "Transforming the Greek e-government environment towards the e-Gov 2.0 era", 2010, pp. 142-149.

[11] I.A. Mergel, C.M. Schweik and J.E. Fountain, "The Transformational Effect of Web 2.0 Technologies on 
Government", Social Science Research Network Working Paper Series, 2009,

[12] C. Danis, M. Bailey, J. Christensen, J. Ellis, T. Erickson, R. Farrell and W. and Kellogg, "Mobile Applications for the Next Billions: A Social Computing Application and a Perspective on Sustainability", 2009,

[13] J. Charlton, "Public sector use of social media takes off", Public Leaders Network: Engagement | guardian.co.uk, 2011(July, 06), 2011,.

[14] D. de Kool and J. van Wamelen, "Web 2.0: A New Basis for E-Government?", Information and Communication Technologies: From Theory to Applications, 2008. ICTTA 2008. 3rd International Conference on, 2008, pp. 1-7.

[15] M. Dadashzadeh, "Social Media In Government: From eGovernment To eGovernance", Journal of Business \& Economics Research (JBER), 8(11), 2010,.

[16] B.E. Dixon, "Towards E-Government 2.0: An Assessment of Where E-Government 2.0 is and Where It Is Headed", Public Administration and Management, 15(2), 2010, pp. 418-454.

[17] S. Aghaei, M.A. Nematbakhsh and H.K. Farsani, "Evolution Of The World Wide Web: From Web 1.0 To Web 4.0", International Journal of Web \& Semantic Technology, 3(1), 2012, pp. 1-10.

[18] A. Kambil, "What is your Web 5.0 strategy?", J.Bus.Strategy, 29(6), 2008, pp. 56-58.

[19] Z. Irani and P.E.D. Love, "Information systems evaluation: A crisis of understanding", 2008, pp. 20.

[20] B. Farbey, F.F. Land and D. Targett, ,How to Assess your IT Investment: A Study of Methods and Practice,Butterworth-Heinmann, 1993.

[21] D. Mintz, "Government 2.0-Fact or Fiction?", Public Manager, 36(4), 2008, pp. 21-21-24.

[22] D. Wilson W., X. Lin, P. Longstreet and S. Sarker, "Web 2.0: A Definition, Literature Review, and Directions for Future Research", 2011, pp. 368.

[23] C. Hakim, ,Research Design: Strategies and Choice in the Design of Social Research,Allen and Unwin, 1987.

[24] R.K. Yin, ,Case Study Research: Design and Methods,Sage, 1994.

[25] P. Atkinson and M. Hammersley, "Ethnography and participant observation", 1994, pp. 248-261.

[26] M.D. Myers, "Qualitative Research in Information Systems", MIS Quarterly, 21(2), 1997, pp. pp. 241-242.

[27] A. Molla, R. Heeks and I. Balcells, "Adding Clicks To Bricks: A Case Study Of E-Commerce Adoption By A Catalan Small Retailer", European Journal Of Information Systems, 15(4), 2006, pp. 424-438.

[28] T.D. Jick, "Mixing Qualitative and Quantitative Methods: Triangulation in Action", Adm.Sci.Q., 24(4), 1979, pp. 602-611.

[29] S.L. Pan and B. Tan, "Demystifying case research: A structured-pragmatic-situational (SPS) approach to conducting case studies", Information and Organization, 21(3), 2011, pp. 161-176.

[30] T. Ramanathan, , The role of organisational change management in offshore outsourcing of information technology services: qualitative case studies from a multinational,Universal Publishers, 2009.

[31] C. Urquhart, "Qualitative research in IS",(An encounter with grounded theory: tackling the practical and philosophical issues), 2001, pp. 104-140.

[32] M.P. Gupta and D. Jana, "E-government evaluation: a framework and case study", Government Information Quarterly, 20(4), 2003, pp. 365-387.

[33] Z. Irani and P.E.D. Love, "The Propagation of Technology Management Taxonomies for Evaluating
Investments in Information Systems", J.Manage.Inf.Syst. 17(3), 2001, pp. 161-177.

[34] S. Shang and P.B. Seddon, "Assessing and managing the benefits of enterprise systems: the business manager's perspective", Information Systems Journal, 12(4), 2002, pp. 271-299.

[35] A. Evangelidis, "FRAMES - A Risk Assessment Framework for e-Services", Electronic Journal of $e$ Government, 2(1), 2004, pp. 21-30.

[36] P. Schwartz, "When good companies do bad things", Strategy \& Leadership, 28(3), 2000, pp. 4-11.

[37] E. Buchanan and E. Luck, "The electronic village: The digital challenges in communication strategies for sporting organization", International Journal of Business Environment, 2(2), 2008, pp. 258-279.

[38] B. Hochstrasser, "Justifying IT investments", Conference Proceedings: Advanced Information Systems, The New Technologies in Today's Business Environment, 1992, pp. 17-28.

[39] J.C. Bertot, P.T. Jaeger and D. Hansen, "The impact of polices on government social media usage: Issues, challenges, and recommendations", Government Information Quarterly, 29(1), 2012, pp. 30-40.

[40] A. Bin Al-Tameem, P. Chittikala and P. Pichappan, "A study of AJAX vulnerability in Web 2.0 applications", Applications of Digital Information and Web Technologies, 2008. ICADIWT 2008. First International Conference on the, 2008, pp. 63-67.

[41] N. Huijboom, T. Broek, V. Frissen, L. Kool, B Kotterink, M.M. Nielsen and J. Millard, "Public Services 2.0: Impact of Social Computing on Public Services", 2009,.

[42] P. DiMaggio, E. Hargittai, W.R. Neuman and J.P. Robinson, "Social Implications of the Internet", Annual Review of Sociology, 27, 2001, pp. pp. 307-336.

[43] W.H. Delone and E.R. McLean, "The DeLone and McLean Model of Information Systems Success: A Ten-Year Update", J.Manage.Inf.Syst., 19(4), 2003, pp. 9-30.

[44] C.M. Schweik, I. Mergel, J.R. Sandfort and Z.J. Zhao, "Toward Open Public Administration Scholarship", Journal of Public Administration Research and Theory, 21(suppl 1), 2011, pp. i175-i198.

[45] P. Parycek and M. Sachs, "Open Government Information Flow in Web 2.0", European Journal of ePractice, 9(1), 2010, pp. 1-70.

[46] B.L. Myers, L.A. Kappelman and V.R. Prybutok, "A comprehensive model for assessing the quality and productivity of the information system function: towards a theory for information systems assessment", Information Resources Management Journal, 10(1), 1997, pp. 6-25.

[47] H. Chen, S. Thoms and T. Fu, "Cyber extremism in Web 2.0: An exploratory study of international Jihadist groups", Intelligence and Security Informatics, 2008. ISI 2008. IEEE International Conference on, 2008, pp. 98-103.

[48] A. Meijer and M. Thaens, "Alignment 2.0: Strategic use of new internet technologies in government", Government Information Quarterly, 27(2), 2010, pp. 113-121.

[49] S. Grabner-Krauter, "Web 2.0 Social Networks: The Role of Trust", Journal of Business Ethics, 90(4), 2009, pp. 505-522. 